\title{
Extraneural Glioblastoma Metastasis: A Case Report
}

\author{
*Selcuk Demiral, Omer Sager, Ferrat Dincoglan, Bora Uysal, Hakan Gamsiz, Yelda Elcim, Bahar Dirican and \\ Murat Beyzadeoglu
}

Department of Radiation Oncology, University of Health Sciences, Turkey

Submission: October 03, 2017; Published: October 23, 2017

"Correspondence Address: Selcuk Demiral, Associate Professor, Department of Radiation Oncology, Gulhane Medical Faculty, University of Health Sciences, gn.tevfik saglam cad. 06018, etlik, kecioren Ankara, Turkey, Tel: +90 312304 4689; Fax: +90 312304 4680; Email: drs.demiral@hotmail.com

\begin{abstract}
Glioblastomas comprise the most common and the most malignant of primary brain tumors with a dismal prognosis. While local failure is very common even after definitive multimodality management, extracranial distant metastasis is extremely infrequent due to the absence of lymphatic drainage. In this case report, we present a 44-year-old male patient presenting with an intracranial lesion who was diagnosed to have World Health Organization (WHO) grade II oligodendroglioma following subtotal excision. Conventionally fractionated radiotherapy at a dose of 54 Gy was delivered to the local cranium after surgery. After 3 years of follow-up without progression, he was diagnosed with recurrent disease and the histopathological assessment revealed a WHO grade IV glioblastoma with malignant transformation. He had bone metastasis together with an involved neck node by direct extension. Symptomatic relief was achieved after salvage chemoirradiation. The patient is still alive after 4 years from the first diagnosis. Extracranial neck node metastasis together with bone metastasis of glioblastoma may be seen though very rarely reported in the literature. Substantial improvement in symptoms may be achieved with multimodality management in the setting of the very rare occurrence of extraneural glioblastoma metastasis.
\end{abstract}

Keywords: Glioblastoma; Metastasis; Extraneural; Radiotherapy

Abbreviations: WHO: World Health Organization; Gy: Gray

\section{Introduction}

Malignant gliomas including World Health Organization (WHO) grade IV glioblastoma and WHO grade III anaplastic astrocytoma, mixed anaplastic oligoastrocytoma, and anaplastic oligodendroglioma have an incidence of approximately 5/100000 [1]. Glioblastomas may be classified as primary and secondary glioblastomas. Glioblastoma is the most agressive form of primary brain tumors which usually occurs "de novo" or by the malignant transformation of low-grade tumors in several years [2].
T1 magnetic resonance imaging (MRI) shows the anatomy while the T2 MRI shows edema and infiltration of brain parenchyma. MRI typically reveals peripheral enhancement with central necrosis, and T2/FLAIR shows increased signal intensity with vasogenic edema and tumor infiltration. Standart treatment is maximal surgery followed by chemoradiotherapy. In this case report, a very rare occurence of extraneural cervical lymph node and vertebral metastasis of glioblastoma is presented with comprehensive literature review.

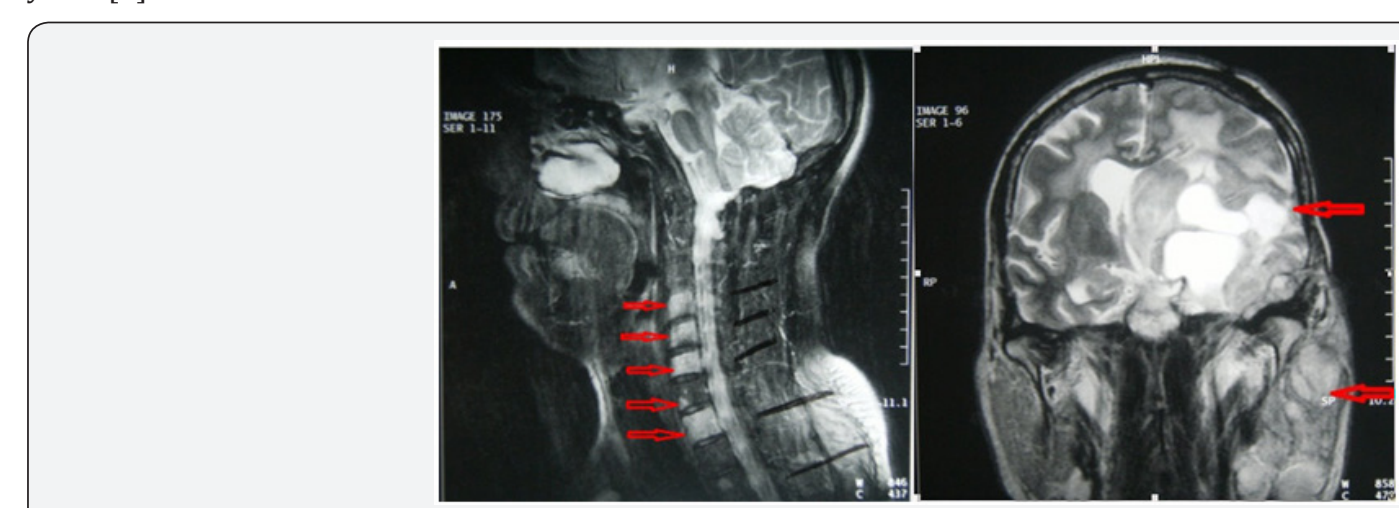

Figure 1: Intracranial lesion, metastatic cervical lymph nodes, and bone metastasis of the glioblastoma patient shown on MRI. 


\section{Case Report}

A 44-year old male patient with complaints of headache and right-sided paresis was referred to the Neurosurgery department. Brain MRI revealed a left parieto-temporal mass and he underwent a subtotal resection. Histopathological assessment revealed a WHO Grade II Oligodendroglioma. He was referred to the Radiation Oncology Department and partial brain irradiation of 54 Gy was delivered. He was followed up periodically after radiotherapy. After 3 years of follow-up without progression, he had complaints of a left-sided neck mass. Neck ultrasound revealed a cystic lymphadenopathy of $28 \times 18 \mathrm{~mm}$ on left cervical neck region. Brain MRI then revealed $7 \times 7 \times 9 \mathrm{~cm}$ cystic residual mass in the left temporal lobe, left centrum semiovale, left basal ganglia which infiltrated the left nasopharyngeal wall with a large edema. Figure 1 shows the intracranial lesion, metastatic cervical lymph nodes, and cervicothoracic bone metastasis of the glioblastoma patient.

Neck MRI revealed multiple left cervical adenopathies and metastasis at the cervicothoracic vertebrae. Bone scan confirmed the bone metastasis including sacroiliacs. The neck adenopathy excision was performed and a histopathological diagnosis of glioblastoma with metastatic oligodendroglial component was revealed on histopathologic assessment. The additional radiation dose to be delivered to the lesion after 3 years from the initial radio therapy course of 54 Gy was calculated, and he was delivered 20 Gy partial brain reirradiation, 60 Gy neck irradiation, and 30 Gy bilateral sacroiliac bone irradiation concurrent with $75 \mathrm{mg} / \mathrm{m} 2$ temozolomide was followed by adjuvant temozolomide $200 \mathrm{mg} / \mathrm{m} 2$ at the first 5 consecutive days of every 28-day cycles. Symptomatic relief was achieved after salvage chemoirradiation. The patient is still alive after 4 years from the first diagnosis.

\section{Discussion}

Extracranial metastasis of glioblastoma is an extremely rare event, particularly in elderly patients $[3,4]$. Pasquier et al. reported metastasis rates of $51 \%$ in the regional lymph nodes, $60 \%$ in lung and the pleura, $31 \%$ in bones, and $22 \%$ in the liver [5]. Even simultaneous leptomeningeal and intramedullary metastases have been described in the literature [6]. Metastasis of glioblastoma is uncommon due to the lack of cerebral lymphatic drainage. Intracranial sinuses are covered by thick dural membr an which makes tumor infiltration difficult. Intracerebral veins are thin-walled and may be collapsed due to compression before being penetrated by the enlarging tumor. The immunological response of the host organ against the neuroglial tumor cells may prevent extra-central nervous system dissemination [7]. Another explanation is the short life expectancy of patients with glioblastoma.

Extracranial metastasis was defined in patients who underwent stereotactic biopsies, and rarely in patients who didn't have a craniotomy before [7]. Distant metastasis usually develops after craniotomy through direct contact with dural veins leading to extracerebral extension [8-10]. If the tumor infiltrates dura mater at middle cranial fossa, metastases tend to extend to lungs and pleura since meningeal venous system flows towards internal jugular vein [8]. Hematogenous metastases may be seen at bones, mostly in the vertebrae [3]. Lymph node metastasis occurs through the relations between perineural area and the lymphatic plexuses [5]. In our case, brain and neck MRI and CT revealed left neck lymphadenopathy, direct invasion to left nasopharyngeal wall, and involvement of cervicothoracic vertebrae. Extracranial metastasis was confirmed by lymph node biopsy which revealed metastasis of glioblastoma. In conclusion, extracranial neck node metastasis and bone metastasis of glioblastoma may be seen though very rarely reported in the literature. Substantial improvement in symptoms may be achieved with multimodality management in the setting of rarely seen extraneural glioblastoma metastasis.

\section{Conflict of Interest}

There is no conflict of interest.

\section{References}

1. Stupp R, Tonn JC, Brada M, Pentheroudakis G ESMO Guidelines Working Group (2010) High grade malignat glioma: ESMO Clinical Practice guidelines for diagnosis, treatment and follow-up. Ann Oncol 21(5): 190-193.

2. Ulutin C, Fayda M, Aksu G, Cetinayak O, Kuzhan O, et al. (2006) Primary glioblastoma multiforme in younger patients: a single-institution experience. Tumori 92(5): 407-411.

3. Mihara F, Ikeda M, Rothman MI, Numaguchi Y, Kristt D (1994) Vertebral body metastasis of glioblastoma multiforme with epidural mass formation. Contrast-enhanced MRI study. Clin Imaging 18(4): 386-389.

4. Piccirilli M, Brunetto GM, Rocchi G, Giangaspero F, Salvati M (2008) Extra central nervous system metastases from cerebral glioblastoma multiforme in elderlypatients. Clinico-pathological remarks on our series of seven cases and critical review of the literature. Tumori 94(1): 40-51.

5. Pasquier B, Pasquier D, N'Golet A, Panh MH, Couderc P (1980) Extraneural metastases of astrocytomas and glioblastomas: clinicopathological study of twocases and review of literature. Cancer 45(1): 112-125.

6. Scoccianti S, Detti B, Meattini I, Iannalfi A, Sardaro A, et al. (2008) Symptomatic leptomeningeal and intramedullary metastases from intracranial glioblastoma multiforme: a case report. Tumori 94(6): 877-881.

7. Newton HB, Rosenblum MK, Walker RW (1992) Extraneural metastases of infratentorial glioblastoma multiforme to the peritoneal cavity. Cancer 69(8): 2149-2153.

8. Utsuki S, Tanaka S, Oka H, Iwamoto K, Sagiuchi T, et al. (2005) Glioblastoma multiforme metastasis to the axis. Case report. J Neurosurg 102(3): 540-542.

9. Frappaz D, Mornex F, Saint-Pierre G, Ranchere-Vince D, Jouvet A, et al. (1999) Bone metastasis of glioblastoma multiforme confirmed by fine needle biopsy. Acta Neurochir (Wien) 141(5): 551-552.

10. Beauchesne P, Soler C, Mosnier JF (2000) Diffuse vertebral body metastasis from a glioblastoma multiforme: a technetium- $99 \mathrm{~m}$ Sestamibi single-photon emission computerized tomography study. J 
This work is licensed under Creative Commons Attribution 4.0 License DOI: $10.19080 /$ CTOIJ.2017.07.555715

\section{Your next submission with Juniper Publishers} will reach you the below assets

- Quality Editorial service

- Swift Peer Review

- Reprints availability

- E-prints Service

- Manuscript Podcast for convenient understanding

- Global attainment for your research

- Manuscript accessibility in different formats

( Pdf, E-pub, Full Text, Audio)

- Unceasing customer service

Track the below URL for one-step submission https://juniperpublishers.com/online-submission.php 